\title{
Impact of social determinants on antiretroviral therapy access and outcomes entering the era of universal treatment for people living with HIV in Italy
}

Annalisa Saracino ${ }^{1 *}$ D, Mauro Zaccarelli ${ }^{2}$, Patrizia Lorenzini ${ }^{2}$, Alessandra Bandera ${ }^{3}$, Giulia Marchetti ${ }^{4}$, Francesco Castelli ${ }^{5}$, Andrea Gori ${ }^{9}$, Enrico Girardi ${ }^{6}$, Cristina Mussini ${ }^{7}$, Paolo Bonfanti ${ }^{8}$, Adriana Ammassari ${ }^{2}$, Antonella d'Arminio Monforte ${ }^{4}$, for the Icona Foundation Study Group

\begin{abstract}
Background: Social determinants are known to be a driving force of health inequalities, even in high income countries. Aim of our study was to determine if these factors can limit antiretroviral therapy (ART) access, outcome and retention in care of people living with HIV (PLHIV) in Italy.

Methods: All ART naivve HIV+ patients (pts) of Italian nationality enrolled in the ICONA Cohort from 2002 to 2016 were included. The association of socio-demographic characteristics (age, sex, risk factor for HIV infection, educational level, occupational status and residency area) with time to: ART initiation (from the first positive anti-HIV test), ART regimen discontinuation, and first HIV-RNA $<50 \mathrm{cp} / \mathrm{mL}$, were evaluated by Cox regression analysis, Kaplan Meier method and log-rank test.
\end{abstract}

Results: A total of $8023 \mathrm{HIV}+$ pts (82\% males, median age at first pos anti-HIV test 36 years, IQR: 29-44) were included: 6214 (77.5\%) started ART during the study period. Women, people who inject drugs (PWID) and residents in Southern Italy presented the lowest levels of education and the highest rate of unemployment compared to other groups. Females, pts aged $>50 \mathrm{yrs}$., unemployed vs employed, and people with lower educational levels presented the lowest CD4 count at ART initiation compared to other groups. The overall median time to ART initiation was 0.6 years (yrs) (IQR 0.1-3.7), with a significant decrease over time [2002-2006 = 3.3 yrs. (0.2-9.4); 2007-2011 = 1.0 yrs. (0.1-3.9); 2012$2016=0.2$ yrs. $(0.1-2.1), p<0.001]$. By multivariate analysis, females $(p<0.01)$ and PWID $(p<0.001)$, presented a longer time to ART initiation, while older people $(p<0.001)$, people with higher educational levels $(p<0.001)$, unemployed $(p=0.02)$ and students $(p<0.001)$ were more likely to initiate ART. Moreover, PWID, unemployed vs stable employed, and pts. with lower educational levels showed a lower 1-year probability of achieving HIV-RNA suppression, while females, older patients, men who have sex with men (MSM), unemployed had higher 1-year risk of first-line ART discontinuation.

Conclusions: Despite median time to ART start decreased from 2002 to 2016, socio-demographic factors still contribute to disparities in ART initiation, outcome and durability.

Keywords: Social determinants, HIV, Antiretroviral therapy, ICONA

\footnotetext{
* Correspondence: annalisa.saracino@uniba.it

${ }^{1}$ Clinic of Infectious Diseases, University of Bari, Piazza G. Cesare, 11 -, 70124

Bari, Italy

Full list of author information is available at the end of the article
}

(c) The Author(s). 2018 Open Access This article is distributed under the terms of the Creative Commons Attribution 4.0 International License (http://creativecommons.org/licenses/by/4.0/), which permits unrestricted use, distribution, and reproduction in any medium, provided you give appropriate credit to the original author(s) and the source, provide a link to the Creative Commons license, and indicate if changes were made. The Creative Commons Public Domain Dedication waiver (http://creativecommons.org/publicdomain/zero/1.0/) applies to the data made available in this article, unless otherwise stated. 


\section{Background}

Antiretroviral therapy (ART) is now recommended worldwide for all people living with HIV (PLHIV), regardless of their CD4 cell count [1]. However, barriers to ART access for PLHIV do exist, with important differences among countries, especially according to socio-economic levels and organization models of national healthcare systems [2]. These disparities can affect the probability of reaching the "90-90-90" target fixed by UNAIDS for 2030 (90\% diagnosed individuals of all PLHIV, 90\% treated patients, and 90\% PLHIV achieving viral suppression) [3].

Even in high income countries, social determinants are known to be a driving force of health inequalities [4]. In the setting of HIV infection, demographic and socioeconomic factors can limit the access to testing, treatment, and retention in care and, consequently, reduce survival of PLHIV [5]. Entering the era of universal ART for all HIV people living with HIV, we can hypothesize that these factors could have an even greater impact on disparities in ART access compared to past years.

In 2015, the proportion of people newly diagnosed with HIV and presenting with $<200 \mathrm{cell} / \mu \mathrm{L}$ CD4 was $36.6 \%$ in Italy, whereas proportion of people with CD $4<350$ cell/ $\mu \mathrm{L}$ was $54.5 \%$ [6]. In a previous study from the ICONA (Italian Cohort Naïve Antiretrovirals) cohort, among socio-demographic factors, migrant status was already demonstrated to be associated with barriers to ART initiation and with increased risk of treatment failure compared to natives [7]. However, other social or behavioral determinants, including gender $[8,9]$, poor education $[10,11]$, unemployment [12], social exclusion within special population groups, e.g. people who inject drugs (PWID), need to be considered [13].

Moreover, also in people accessing ART and adhering to therapy, lifestyle differences can affect chances to respond to ART, occurrence of side effects and co-morbidities in PLHIV [14].

Aim of our study was to determine if social determinants influence ART access, outcome and retention in care of PLHIV in spite of a context of public healthcare. The knowledge of factors which define the "social vulnerability" can allow to allocate resources and plan for interventions in order to reduce disparities which impact survival of persons living with HIV.

\section{Methods}

The ICONA Foundation Study is an observational cohort of people living with HIV who are antiretroviral naïve at the time of enrolment. This cohort was set up in January 1997 and currently consists of over 14,000 patients from 50 Italian infectious disease reference units. Demographic and socio-behavioral data, initiation and discontinuation dates of each antiretroviral drug, HIV-viral load and CD4 cell count every 3-6 months, AIDS defining diseases according to Centers for Disease Control and Prevention (CDC) criteria as well as non-HIV related diseases and death are recorded for all enrolled participants. Further details are available at http://www.fondazioneicona.org/.

In the present study, all ART naive PLHIV of Italian nationality enrolled in the ICONA Cohort from 2002 to 2016 were included. The following socio-demographic characteristics were retrieved and analyzed for their potential association with the study endpoints: age, gender (male, female), risk factor for HIV infection [heterosexuals (HS), men who have sex with men (MSM), people who inject drugs (PWID)], educational level, occupational status and residency area. Taking into account the structure of the Italian education system, and according to the UNESCO/International Standard Classification of Education standard classification (ISCED) [15], the educational level was categorized into four categories: primary school (corresponding to ISCED 0); junior secondary school (ISCED 1); high secondary school (ISCED $2-3$ ); tertiary school (university and similar) (ISCED $\geq 4$ ). The occupational status was classified into seven categories as follows: full-time worker, temporary employed, self employed, unemployed, student, retired, housewife (defined as women only managing household affairs without having paid employment). The residency area was categorized in Northern, Central and Southern Italy.

Patients who did not attend visits for $\geq 18$ months were defined as lost to follow-up.

\section{Statistical analysis}

The study time was divided into 3-5 years periods: 2002-2006; 2007-2011; 2012-2016, in order to compare different ART treatment period, according to guidelines changes and progressive availability of new antiretroviral drugs. Patients' characteristics were compared according to time period using Chi square test for trend for categorical variables and Kruskal Wallis test for continuous parameters.

Three different end-points were evaluated:

a) probability of ART initiation from the first positive anti-HIV test;

b) virological response defined as first HIV-RNA $<50$ $\mathrm{cp} / \mathrm{mL}$ after therapy start;

c) first ART regimen discontinuation for any causes.

For the evaluation of the endpoints (b) and (c) only patients with $\geq 1$ year of follow-up were included.

The association of socio-demographic characteristics (age, sex, risk factor for HIV infection, educational level, occupational status and residency area, smoking habit) and clinical parameters (CDC stage, CD4 and HIV RNA value and pregnancy) with three end-points were evaluated by 
Cox regression analysis. 1-year probability was evaluated by Kaplan Meier method and log-rank test was used to compare survival curves.

\section{Results}

Baseline patient characteristics

A total of 8023 HIV-positive patients (82\% males, median age at first positive anti-HIV test: 36 years, IQR: 29-44) were included in the ICONA observational database in the period 2002-2016, whose characteristics are shown in Table 1, overall and according to the three different study periods. Median age at time of enrolment, proportion of males and MSM increased over time. Moreover, a growing number of people with high secondary and tertiary level of education but a decreasing number of full employed workers was observed in last period (2012-2016). The percentage of pre-treatment AIDS events and very late presenter patients $(<200 \mathrm{CD} 4 / \mu \mathrm{l})$ decreased passing from the first to the last period from 13 and $26 \%$ to 7 and $17 \%$, respectively.

The distribution of educational level and occupational status according to gender, mode of HIV transmission and area of residency are shown in Fig. 1. Women, PWID and residents in Southern Italy presented the lowest levels of education and the highest rate of unemployment compared to other groups.

The median CD4 cell count at time of enrolment in the ICONA cohort according to the investigated socio-demographic variables is summarized in Table 2 In particular, women, people who acquired the HIV infection through heterosexual contacts, older individuals, and housewives, were more at risk of late presentation. Moreover, the risk of late presentation decreased with increasing educational level.

The number of lost to follow-up patients according to the main study variables is reported in Table 3; female gender, younger age, PWID, low educational level and unemployment were associated with a higher drop-out rate.

\section{Time to ART initiation}

A total of 6214 cohort participants (77.5\%) started ART during the study period after a median time to ART initiation of 0.6 years (IQR 0.1-3.7). The median of years from first HIV test and cART initiation decrease over time $[2002-2006=3.3$ years $(0.2-9.4)$; $2007-2011=1.0$ years $(0.1-3.9) ; 2012-2016=0.2$ years (0.1-2.1), $p<0.001]$.

Median CD4 cell count levels at time of ART initiation are also showed in Table 2. Females, patients aged $>50$ years, housewife and retired, and people with lower educational levels presented the lowest CD4 count at ART initiation compared to other groups.

Factors associated with the probability of ART initiation by multivariable analysis are reported in Fig. 2: females vs. males, PWID compared to HS showed a reduced probability of starting therapy. On the other hand, unemployed people and students compared to full time workers, older people, people with higher educational levels, and residents in the Central and Southern area of the country were more likely to initiate ART.

\section{Response to ART}

A total of 5792 patients starting ART during the study period presented at least 1 year of follow-up and were included in the analysis on the response to ART. 5111 (88.2\%) cohort participants reached at least one HIV-RNA $<50 \mathrm{cp} / \mathrm{mL}$. After adjustment for potential confounders, intravenous drug use compared to heterosexual as mode of HIV transmission, unemployment and temporary employment vs full time work, and residency in Southern and Central vs Northern Italy were associated with a lower probability of achieving HIV-RNA suppression. On the contrary, patients with higher educational levels (high school or university, ISCED 2-4) were more likely to reach an undetectable viral load than their counterparts (Fig. 3).

\section{ART discontinuation}

A total of 3079 out of 5792 patients (53\%) changed or interrupted first line-regimen during the study period. In Fig. 4, factors associated with first-line ART discontinuation by multivariable analysis are summarized. MSM presented a higher risk of first-line ART discontinuation along with patients aged $40-50$ and more than 50 years vs $<30$, females vs males, unemployed people compared to full time workers. On the contrary, housewives and residents in Central and Southern Italy presented a lower rate of therapy discontinuation than other groups, while no association was observed between educational level and therapy interruption.

\section{Discussion}

Socio-demographic factors are an important cause of health inequalities, even in high income countries adopting universal health care systems [5]. In Italy, both HIV testing and ART are free of charge for all individuals, independently on disease stage, work conditions or other economical issues. Data from the national health institute demonstrated a satisfactory framework of the HIV treatment cascade in our country, which appears to be very close to WHO targets, showing that in 2014 92\% of people diagnosed with HIV were in ART treatment, $87.7 \%$ of whom with suppressed HIV viremia [6]. According to changes in international and national guidelines, which progressively suggested to start ART at higher CD4 count overtime, our data demonstrate that, 
Table 1 Socio-demographic characteristics of patients according to years of starting CART or year of last observation

\begin{tabular}{|c|c|c|c|c|c|}
\hline & $\begin{array}{l}\text { Overall } \\
N=8023\end{array}$ & $\begin{array}{l}2002-2006 \\
N=1543\end{array}$ & $\begin{array}{l}2007-2011 \\
N=2166\end{array}$ & $\begin{array}{l}2012-2016 \\
N=4314\end{array}$ & $p$ \\
\hline \multicolumn{6}{|l|}{ Gender, n (\%) } \\
\hline Female & $1434(17.9 \%)$ & $453(29.4 \%)$ & $368(17.0 \%)$ & $613(14.2 \%)$ & \multirow[t]{2}{*}{$<0.001$} \\
\hline Male & $6589(82.1 \%)$ & $1090(70.6 \%)$ & $1798(83.0 \%)$ & $3701(85.8 \%)$ & \\
\hline \multicolumn{6}{|c|}{ Age at first positive anti-HIV test, n (\%) } \\
\hline$<30$ & $2582(32.2 \%)$ & $682(44.2 \%)$ & $637(29.5 \%)$ & $1263(29.3 \%)$ & \multirow[t]{4}{*}{$<0.001$} \\
\hline $30-40$ & $2646(33.0 \%)$ & $521(33.8 \%)$ & $742(34.4 \%)$ & $1383(32.1 \%)$ & \\
\hline $40-50$ & 1709 (21.3\%) & $221(14.3 \%)$ & $475(22.0 \%)$ & $1013(23.5 \%)$ & \\
\hline$>50$ & 1079 (13.5\%) & $119(7.7 \%)$ & 305 (14.1\%) & $655(15.2 \%)$ & \\
\hline \multicolumn{6}{|c|}{ Mode of HIV transmission, n (\%) } \\
\hline $\mathrm{HS}$ & $2773(34.6 \%)$ & $590(38.2 \%)$ & $816(37.7 \%)$ & 1367 (31.7\%) & \multirow[t]{4}{*}{$<0.001$} \\
\hline PWID & $1131(14.1 \%)$ & $509(33.0 \%)$ & $265(12.2 \%)$ & $357(8.3 \%)$ & \\
\hline MSM & $3528(44.0 \%)$ & $342(22.2 \%)$ & $942(43.5 \%)$ & $2244(52.0 \%)$ & \\
\hline other/unknown & $591(7.4 \%)$ & $102(6.6 \%)$ & $143(6.6 \%)$ & 346 (8.0\%) & \\
\hline \multicolumn{6}{|l|}{ Education } \\
\hline Elementary school & $362(4.5 \%)$ & $162(10.5 \%)$ & $99(4.6 \%)$ & $101(2.3 \%)$ & \multirow[t]{5}{*}{$<0.001$} \\
\hline Junior high school & $1803(22.5 \%)$ & $596(38.6 \%)$ & $528(24.4 \%)$ & 679 (15.7\%) & \\
\hline High school & $2576(32.1 \%)$ & $423(27.4 \%)$ & 708 (32.7\%) & 1445 (33.5\%) & \\
\hline University & $920(11.5 \%)$ & $101(6.6 \%)$ & $217(10.0 \%)$ & $602(14.0 \%)$ & \\
\hline Missing data & $2362(29.4 \%)$ & $261(16.9 \%)$ & $614(28.4 \%)$ & 1487 (34.5\%) & \\
\hline \multicolumn{6}{|l|}{ Employement } \\
\hline Full time worker & 3575 (44.6\%) & $703(45.6 \%)$ & 1100 (50.8\%) & 1772 (41.1\%) & \multirow[t]{9}{*}{$<0.001$} \\
\hline Unemployed & $910(11.3 \%)$ & 307 (19.9\%) & $217(10.0 \%)$ & $386(9.0 \%)$ & \\
\hline Self employed & $1231(15.3 \%)$ & 265 (17.2\%) & 304 (14.0\%) & $662(15.4 \%)$ & \\
\hline Temporary employed & $192(2.4 \%)$ & 75 (4.9\%) & $45(2.1 \%)$ & $72(1.7 \%)$ & \\
\hline Student & $296(3.7 \%)$ & $29(1.9 \%)$ & $75(3.5 \%)$ & $192(4.5 \%)$ & \\
\hline Retired & $256(3.2 \%)$ & $40(2.6 \%)$ & $96(4.4 \%)$ & $120(2.8 \%)$ & \\
\hline Housewife & $233(2.9 \%)$ & $103(6.7 \%)$ & $72(3.3 \%)$ & $58(1.3 \%)$ & \\
\hline Other/unknown & $204(2.5 \%)$ & $18(1.2 \%)$ & $40(1.9 \%)$ & $146(3.4 \%)$ & \\
\hline Missing data & $1126(14.0 \%)$ & $3(0.2 \%)$ & $217(10.0 \%)$ & $906(21.0 \%)$ & \\
\hline \multicolumn{6}{|l|}{ Residency area } \\
\hline Northern Italy & $4540(56.6 \%)$ & $763(49.5 \%)$ & $1226(56.6 \%)$ & $2551(59.1 \%)$ & \multirow[t]{3}{*}{$<0.001$} \\
\hline Central Italy & 2678 (33.4\%) & 517 (33.5\%) & 769 (35.5\%) & 1392 (32.3\%) & \\
\hline Southern Italy & $805(10.0 \%)$ & $263(17.0 \%)$ & $171(7.9 \%)$ & $371(8.6 \%)$ & \\
\hline \multicolumn{6}{|l|}{ Smokers } \\
\hline No & $3589(44.7 \%$ & $532(34.5 \%)$ & $1040(48.0 \%)$ & 2017 (46.8\%) & \multirow[t]{3}{*}{$<0.001$} \\
\hline Yes & $3636(45.3 \%)$ & $787(51.0 \%)$ & $990(45.7 \%)$ & $1859(43.1 \%)$ & \\
\hline Not known & $798(10.0 \%)$ & $224(14.5 \%)$ & $136(6.3 \%)$ & $438(10.2 \%)$ & \\
\hline \multicolumn{6}{|l|}{ CDC stage } \\
\hline C & $714(8.9 \%)$ & 199 (12.9\%) & 219 (10.1\%) & $296(6.9 \%)$ & \multirow[t]{2}{*}{$<0.001$} \\
\hline$A / B$ & 7309 (91.1\%) & $1344(87.1 \%)$ & 1947 (89.9\%) & 4018 (93.1\%) & \\
\hline \multicolumn{6}{|c|}{ Pre treatment CD4 cell/mmc } \\
\hline$<=200$ & 1630 (20.3\%) & $404(26.2 \%)$ & $508(23.5 \%)$ & $718(16.6 \%)$ & \multirow[t]{2}{*}{$<0.001$} \\
\hline $201-350$ & 1952 (24.3\%) & $516(33.4 \%)$ & $699(32.3 \%)$ & 737 (17.1\%) & \\
\hline
\end{tabular}


Table 1 Socio-demographic characteristics of patients according to years of starting CART or year of last observation (Continued)

\begin{tabular}{|c|c|c|c|c|c|}
\hline & $\begin{array}{l}\text { Overall } \\
N=8023\end{array}$ & $\begin{array}{l}2002-2006 \\
N=1543\end{array}$ & $\begin{array}{l}2007-2011 \\
N=2166\end{array}$ & $\begin{array}{l}2012-2016 \\
N=4314\end{array}$ & $p$ \\
\hline $351-500$ & $1761(22.0 \%)$ & $251(16.3 \%)$ & $473(21.8 \%)$ & $1037(24.0 \%)$ & \\
\hline 500-max & $1913(23.8 \%)$ & $308(20.0 \%)$ & $291(13.4 \%)$ & $1314(30.5 \%)$ & \\
\hline Missing data & 767 (9.6\%) & $64(4.2 \%)$ & $195(9.0 \%)$ & $508(11.8 \%)$ & \\
\hline \multicolumn{6}{|c|}{ Pre treatment log10 HIV RNA } \\
\hline$<4$ & $1844(23.0 \%)$ & $385(25.0 \%)$ & $427(19.7 \%)$ & $1032(23.9 \%)$ & \multirow[t]{5}{*}{0.012} \\
\hline $4-4.7$ & $1961(24.4 \%)$ & $379(24.6 \%)$ & $524(24.2 \%)$ & $1058(24.5 \%)$ & \\
\hline $4.8-5.2$ & $1644(20.5 \%)$ & $363(23.5 \%)$ & $478(22.1 \%)$ & $803(18.6 \%)$ & \\
\hline $5.2+$ & $1590(19.8 \%)$ & $316(20.5 \%)$ & $488(22.5 \%)$ & $786(18.2 \%)$ & \\
\hline Missing data & $984(12.3 \%)$ & $100(6.5 \%)$ & $249(11.5 \%)$ & $635(14.7 \%)$ & \\
\hline \multicolumn{6}{|l|}{ Pregnancy status } \\
\hline Not pregnant & $7715(96.2 \%)$ & 1517 (98.3\%) & 2109 (97.4\%) & 4089 (94.8\%) & \multirow[t]{3}{*}{$<0.001$} \\
\hline Pregnant & $30(0.4 \%)$ & $5(0.3 \%)$ & $7(0.3 \%)$ & $18(0.4 \%)$ & \\
\hline Missing data & 278 (3.5\%) & 21 (1.4\%) & 50 (2.3\%) & $207(4.8 \%)$ & \\
\hline
\end{tabular}

for patients enrolled in the ICONA cohort, time to ART initiation significantly decreased from more than 3 years in 2002-2006 up to 0.2 years in the last 4 years. In this context, we aimed to evaluate if social determinants do still play a role in access and response to antiretroviral therapy in PLHIV.

Herein, we limited our analysis to native Italian people in order to avoid that confounding factors related to the status of migrant could influence our results, including language barriers and cultural differences. In a previous paper, however, including patients enrolled in the ICONA cohort as well, an increased risk of both delayed access to ART and virological failure was already demonstrated in migrants living with HIV [7]. Moreover, only patients enrolled in ICONA during a relative recent period (2002-2016) were included in the present study, in order to take into account exclusively modern (and highly potent) antiretroviral regimens.
The results of our analysis clearly evidenced that, even in a country with universal health care coverage as Italy, several social determinants, including female gender, PWID as a risk factor for HIV transmission, low educational level and unemployment, significantly impact both ART access and outcomes. It should be underlined that these variables are also strictly interconnected to each other: in fact, females, PWID and residents in Southern Italy also presented the lowest level of education and the highest rate of unemployment. Although the public health system is freely assured throughout the country since 1978, after a constitutional reform voted in 2001, budget and organization of health services are under regional control. Therefore, many differences in health services may exist among different Italian areas. Based on historical reasons, Northern, Central, and Southern Italy are quite different from an economic and social point of view, with a North-to-South gradient, being in general
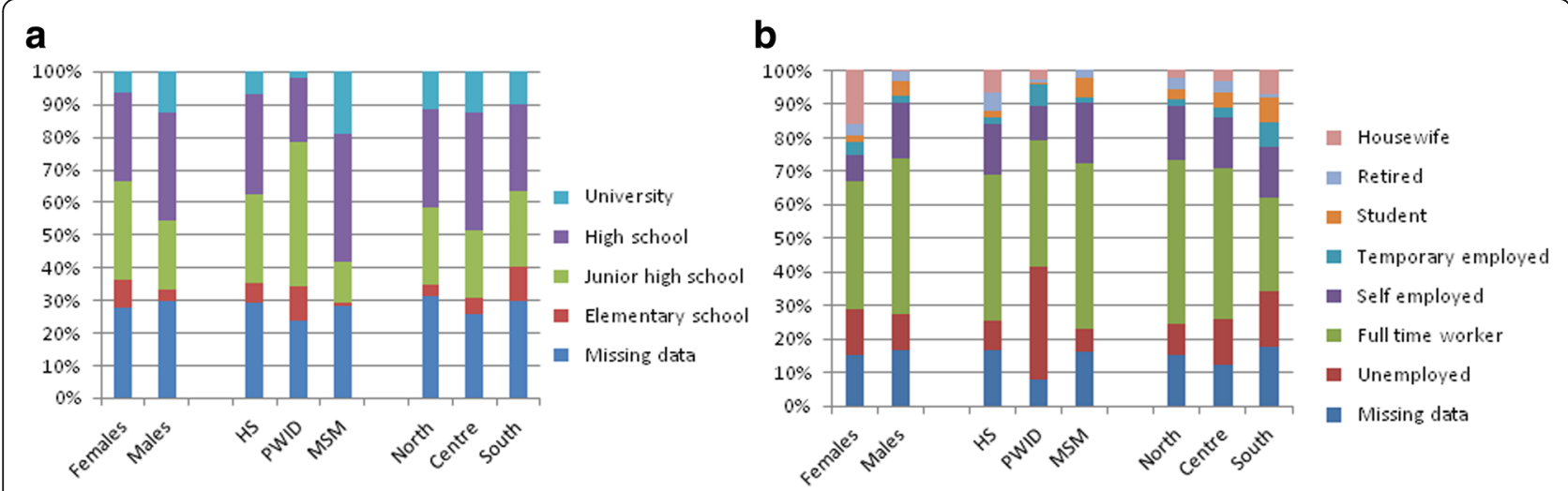

Fig. 1 Distribution of education level (a) and occupational status (b) according to gender, mode of HIV transmission and area of residency 
Table 2 Median CD4 cell count at time of enrolment in the ICONA cohort and at time of ART initiation according to sociodemographic characteristics

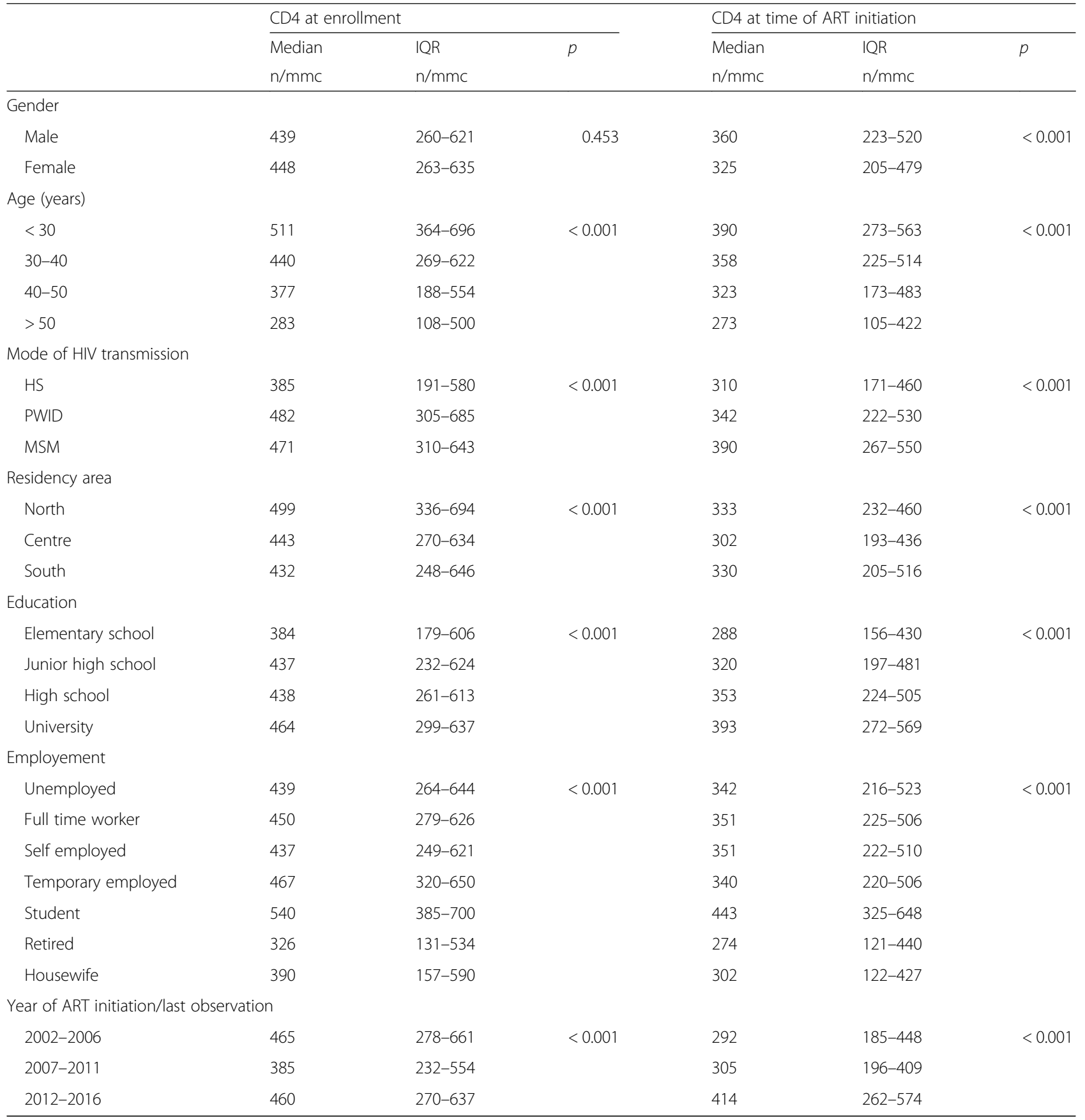

Northern regions the most industrialized areas of the nation.

First, a risk of late presentation was demonstrated for all the above mentioned categories, which was particularly evident for people aged more than 50 years, which is in line with national and international reports $[6,16]$. Similarly, older patients started ART with significantly lower CD4 cell number compared to younger subjects and, in parallel, they presented significantly longer time to ART initiation since the first anti-HIV positive test. People $>50$ years old had the same mode of HIV acquisition of younger people, but they may be less aware of their HIV status. Moreover, HIV testing is probably less recommended by health care providers in this group than in young adults [17]. However, old people need to be recognized as a high risk group as they present 
Table 3 Drop-out rate according to socio-demographic characteristics

\begin{tabular}{|c|c|c|}
\hline & $\mathrm{N}^{\circ}$ of lost to follow-up & $P$ \\
\hline \multicolumn{3}{|l|}{ Gender } \\
\hline Male & $1373(20.8 \%)$ & \multirow[t]{2}{*}{$<0.001$} \\
\hline Female & $423(29.5 \%)$ & \\
\hline \multicolumn{3}{|c|}{ Age at first positive anti-HIV test } \\
\hline$<30$ & 797 (30.9\%) & \multirow[t]{4}{*}{$<0.001$} \\
\hline $30-40$ & $566(21.4 \%)$ & \\
\hline $40-50$ & $258(15.1 \%)$ & \\
\hline$>50$ & $168(15.6 \%)$ & \\
\hline \multicolumn{3}{|l|}{ Mode of HIV transmission } \\
\hline $\mathrm{HS}$ & $571(20.6 \%)$ & \multirow[t]{4}{*}{$<0.001$} \\
\hline PWID & $552(48.8 \%)$ & \\
\hline MSM & $530(15.0 \%)$ & \\
\hline other/unknown & $143(24.2 \%)$ & \\
\hline \multicolumn{3}{|l|}{ Residency area } \\
\hline North & $929(20.5 \%)$ & \multirow[t]{3}{*}{$<0.001$} \\
\hline Centre & $560(20.9 \%)$ & \\
\hline South & 307 (38.1\%) & \\
\hline \multicolumn{3}{|l|}{ Education } \\
\hline Elementary school & $141(39.0 \%)$ & \multirow[t]{5}{*}{$<0.001$} \\
\hline Junior high school & $574(31.8 \%)$ & \\
\hline High school & $484(18.8 \%)$ & \\
\hline University & $129(14.0 \%)$ & \\
\hline Missing & $468(19.8 \%)$ & \\
\hline \multicolumn{3}{|l|}{ Employment } \\
\hline Unemployed & $755(21.1 \%)$ & \multirow[t]{9}{*}{$<0.001$} \\
\hline Full time worker & $347(38.1 \%)$ & \\
\hline Self employed & $264(21.4 \%)$ & \\
\hline Temporary employed & $72(37.5 \%)$ & \\
\hline Student & $67(22.6 \%)$ & \\
\hline Retired & $50(19.5 \%)$ & \\
\hline Housewife & $94(40.3 \%)$ & \\
\hline other/unknown & $33(16.2 \%)$ & \\
\hline missing data & $114(10.1 \%)$ & \\
\hline
\end{tabular}

poorer immunologic response compared with younger patients, with higher mortality rates [18]. In our study, ART initiation was more likely with increasing age, even after adjustment for CD4 count. No significant association between age and achievement of viremia suppression on ART after 1 year was demonstrated. Older patients were associated with a more recent year of ART initiation, which was conversely associated with lower risk of discontinuation. From the multivariable analysis, however, after adjusting for year of ART initiation, older age was related to a higher risk of therapy discontinuation, probably due to a higher frequency of side effects and co-morbidities in this patient group. The type of drug ART regimen could also be a possible explanation, as older individuals were more frequently on a protease inhibitor-based regimen ( $42 \%$ compared to $25 \%$ in patients aged $>30$ years, data not shown).

If female gender is a risk factor for late presentation, delayed therapy initiation and poor ART response is controversial in literature [19-21]. In fact, several aspects might contribute to confound results from different cohorts, also depending on the chosen endpoints [19]: firstly, early diagnosis of HIV infection in women is favored by screening programs for HIV during pregnancy; secondly, lower HIV-RNA levels have been observed in women compared to males [20] which could justify better response rates to ART. Finally, regarding the association of gender and mortality for PLHIV, it should be taken into account that women have an overall higher life expectancy compared to men, at least in Western countries. Moreover, in PLHIV, a lower incidence of non-AIDS events in women compared to males has been described [22]. In our study, after controlling for other variables including pregnancy status and HIV viremia levels, females resulted more at risk of delayed ART initiation and therapy discontinuation, even if no differences in response rates to the first year of ART were evidenced. The status of housewife, however, was not associated with the same endpoints in our analysis; on the contrary, they presented a lower rate of therapy discontinuation. No data regarding this association in literature are available to our knowledge.

Among the different risk group categories for HIV acquisition, as expected, people who inject drugs presented a delay in initiation of ART and inferior virological response to therapy; our results are in agreement with the paper of Lesko et al. [13] who demonstrated as PWID, even in recent years, spent a significantly larger amount of time not on ART compared with non-PWID or, when on ART, not virally suppressed, thus greatly contributing to HIV transmission. On the contrary, MSM, who became the most represented group in the last years (52\%), initiated ART at significantly higher CD4 levels than other risk groups; however, MSM resulted more frequently at risk of ART change / interruption compared to other groups.

The economic status of PLHIV is always hard to be determined. Educational level and occupational status, however, can be considered good proxies of such condition [5]. We demonstrated that the educational level has a crucial role of in influencing both access and response to ART in our country. This finding extend previous observations in Italy [23] and in other 


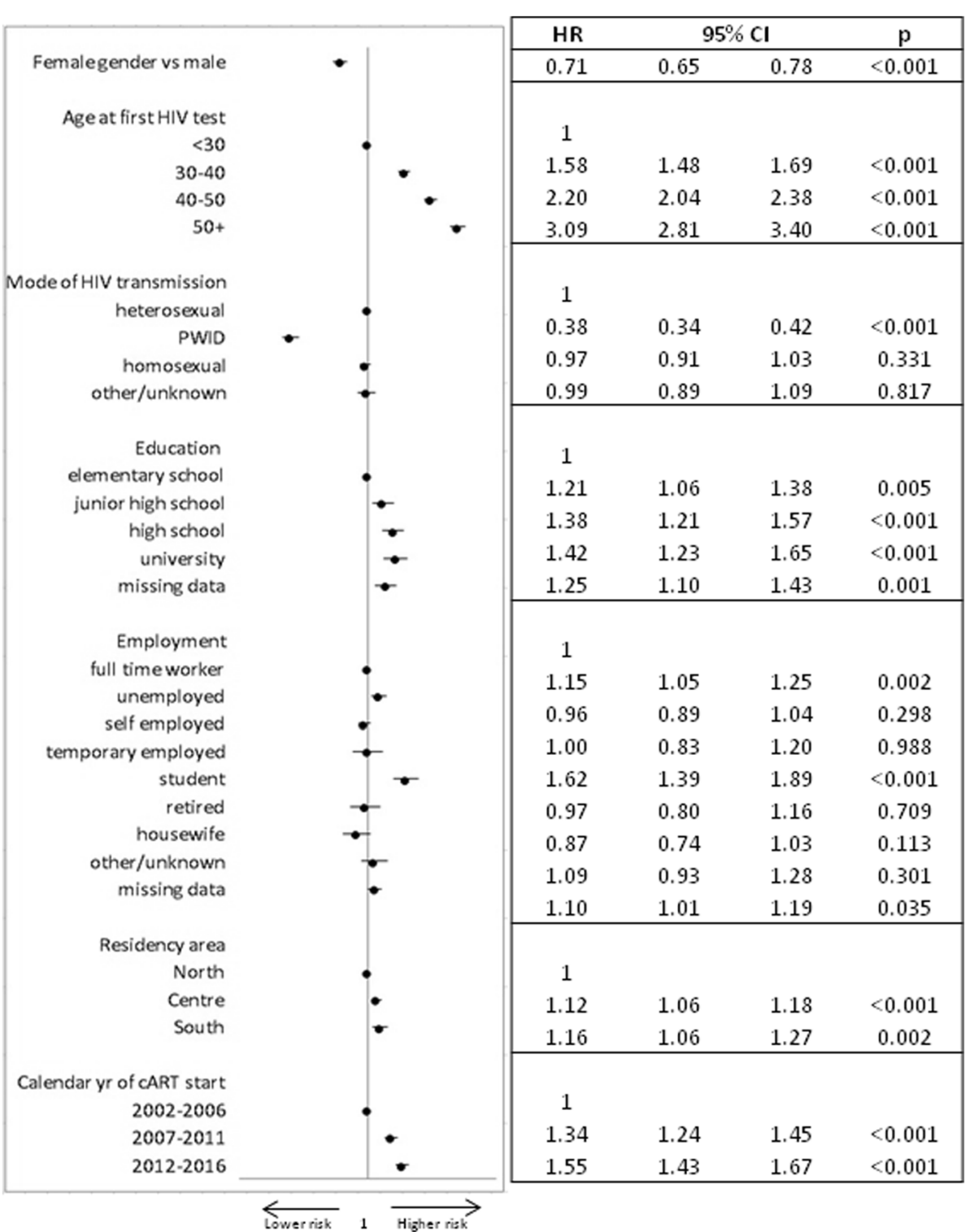

Fig. 2 Multivariable model of factors associated with time to CART start (adjusted for CD4 count, viral load, pregnancy status, smoking)

European countries [24-26], and are in agreement with recent multi-cohort data from the COHERE [10, 11]. In addition, the relationship between occupational status and ART access and outcomes was also analyzed. Very few studies [12, 27] have addressed this point to date, as this information is not registered in the most part of the cohorts enrolling HIV patients. In France [27], a global indicator of social vulnerability including education, employment, and housing stability and comfort, after adjustment for lifestyle factors, psychosocial characteristics (depression, drug using) and known biomedical factors, was associated with mortality in PLHIV. Moreover, unemployment was associated with a reduced sustained virological suppression (e.g. undetectable viral load for $\geq 6$ months) [12]. In our analysis, unemployment was associated with all three endpoints (a longer time to ART initiation, lower chances to reach a suppressed HIV viremia, and higher risk of discontinuation). It must be underlined that work conditions, although considered an excellent proxy of economic status, may change during patient's life and cannot be considered as an independent variable as a poor health status could also cause job loss. However, as only the first year ART response was investigated in the present study, and the occupational status was registered at entry in the cohort, our results can be considered reliable. 


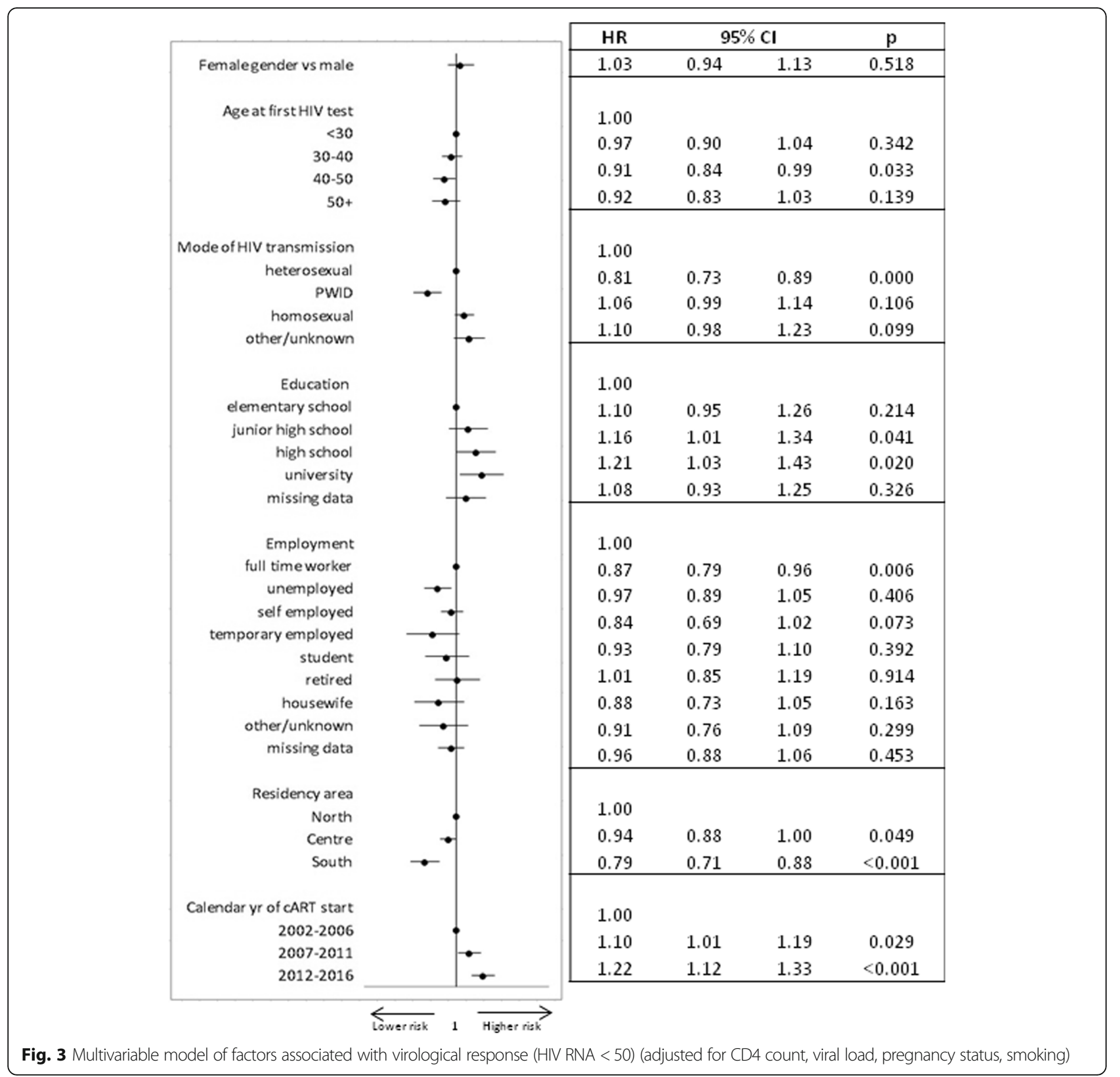

Among lifestyle factors, smoking was not associated with any of the study endpoints in our analysis [14]. All results were adjusted for smoking and pregnancy status. However, other behavioral and clinical factors, including alcoholism or depression, were not targeted in our analysis but could have indirectly influenced our results. In particular, the inclusion of mental health outcomes as part of the ICONA database in the future would be suitable. A high percentage of missing data regarding educational level could have introduced some biases, representing an important limitation of our study. A major limitation is also the lack of information regarding the presence of transgender people in our cohort. In fact, even if sexual orientation and gender identity should be reported the ICONA database, no transgender cohort participants were registered among patients fulfilling inclusion criteria in our study, which seems to suggest that this information was under-reported by clinicians [28, 29].

\section{Conclusions}

In conclusions, notwithstanding median time to ART start decreased from 3.3 to 0.2 years from 2002 to 2016, 


\begin{tabular}{|c|c|c|c|c|c|}
\hline \multirow[b]{2}{*}{ Femalegender vs male } & \multirow[b]{2}{*}{$\bullet$} & HR & \multicolumn{2}{|c|}{$95 \% \mathrm{Cl}$} & \multirow{2}{*}{$\begin{array}{r}p \\
<0.001\end{array}$} \\
\hline & & 1.45 & 1.29 & 1.62 & \\
\hline Age at first HIV test & & 100 & & & \\
\hline$<30$ & • & 1.00 & & & \\
\hline $30-40$ & $\rightarrow$ & 0.94 & 0.86 & 1.04 & 0.241 \\
\hline $40-50$ & $\bullet$ & 1.13 & 1.01 & 1.25 & 0.027 \\
\hline $50+$ & $\multimap$ & 1.17 & 1.03 & 1.34 & 0.018 \\
\hline Mode of HIV transmission & & 1.00 & & & \\
\hline heterosexual & & 1.00 & 0.89 & 1.14 & 0.962 \\
\hline homosexual & - & 1.17 & 1.06 & 1.28 & 0.001 \\
\hline other/unknown & & 1.00 & 0.86 & 1.16 & 0.980 \\
\hline Education & & 1.00 & & & \\
\hline elementary school & & 0.99 & 0.84 & 1.17 & 0.930 \\
\hline junior high school & - & 1.01 & 0.85 & 1.19 & 0.923 \\
\hline $\begin{array}{r}\text { high school } \\
\text { university }\end{array}$ & & 1.08 & 0.89 & 1.32 & 0.420 \\
\hline missing data & $\cdot$ & 0.96 & 0.81 & 1.15 & 0.658 \\
\hline Employment & & 1.00 & & & \\
\hline full timeworker & & 1.18 & 1.04 & 1.34 & 0.008 \\
\hline unemployed & $\bullet$ & 1.04 & 0.94 & 1.15 & 0.451 \\
\hline $\begin{array}{l}\text { self employed } \\
\text { temporary employed }\end{array}$ & 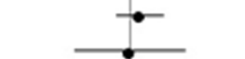 & 1.00 & 0.78 & 1.28 & 0.985 \\
\hline $\begin{array}{r}\text { temporary employed } \\
\text { student }\end{array}$ & & 0.87 & 0.69 & 1.10 & 0.233 \\
\hline retired & & 1.15 & 0.94 & 1.40 & 0.179 \\
\hline housewife & $\longrightarrow$ & 0.73 & 0.59 & 0.90 & 0.003 \\
\hline other/unknown & & 1.20 & 0.94 & 1.52 & 0.143 \\
\hline missing data & 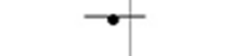 & 0.93 & 0.81 & 1.07 & 0.313 \\
\hline Residency area & & & & & \\
\hline North & • & 1.00 & & & \\
\hline Centre & $\bullet-$ & 0.92 & 0.85 & 0.99 & 0.031 \\
\hline South & $\multimap$ & 0.85 & 0.74 & 0.98 & 0.022 \\
\hline Calendar yr of CART start & & 1.00 & & & \\
\hline $\begin{array}{c}2002-2006 \\
2007-2011\end{array}$ & & 0.65 & 0.59 & 0.71 & $<0.001$ \\
\hline $2012-2016$ & $\rightarrow$ & 0.66 & 0.59 & 0.73 & $<0.001$ \\
\hline
\end{tabular}

Fig. 4 Multivariable model of factors associated with treatment discontinuation for any causes (adjusted for CD4 count, viral load, pregnancy status, smoking)

socio-demographic factors still contribute to important disparities in ART initiation, outcome and durability in PLHIV from Italy. Therefore, a deeper evaluation of socio-economic determinants, possibly using a standardized approach, is needed on one side; on the other side, welfare interventions aiming to reduce the social inequality for fragile populations such as PWID, women, old people, patients with low educational level and unemployed, along with migrants, would indirectly improve the cascade of care for PLHIV. Moreover, it should be underlined that relatively few complete national data regarding continuum of care are available in Italy as in other countries, with wide variation in reporting procedures [30]. Nowadays it becomes more and more important to use consistent and accurate methods for tracking progress towards the achievement of WHO 90-90-90 targets.

\section{Abbreviations}

ART: Antiretroviral Therapy; CDC: Center for Disease Control; HIV: Human Immunodeficiency Virus; HS: Heterosexual; ICONA: Italian Cohort Naïve Antiretrovirals; IQR: Interquartile range; IRB: Institutional Review Board; ISCED: International Standard Classification of Education; MSM: Men who have sex with men; PLHIV: People Living With HIV; PWID: People who inject drugs; UNAIDS: Joint United Nations Programme on HIV/AIDS; 
UNESCO: United Nations Educational, Scientific and Cultural Organization; WHO: World Health Organization

\section{Acknowledgements}

We acknowledge all patients and physicians participating to the ICONA cohort. ICONA Foundation Study Group.

BOARD OF DIRECTORS

M Moroni (Chair), M Andreoni, G Angarano, A Antinori, A d'Arminio Monforte, F Castelli, R Cauda, G Di Perri, M Galli, R lardino, G Ippolito, A Lazzarin, CF Perno, F von Schloesser, P Viale.

SCIENTIFIC SECRETARY.

A d'Arminio Monforte, A Antinori, A Castagna, F Ceccherini-Silberstein, A Cozzi-Lepri, E Girardi, S Lo Caputo, C Mussini, M Puoti.

STEERING COMMITTEE

M Andreoni, A Ammassari, A Antinori, C Balotta, P Bonfanti, S Bonora, M Borderi, MR Capobianchi, A Castagna, F Ceccherini-Silberstein, A Cingolani, P Cinque, A Cozzi-Lepri, A d'Arminio Monforte, A De Luca, A Di Biagio, E Girardi, N Gianotti, A Gori, G Guaraldi, G Lapadula, M Lichtner, S Lo Caputo, G Madeddu, F Maggiolo, G Marchetti, S Marcotullio, L Monno, C Mussini, M Puoti, E Quiros Roldan, S Rusconi, A Saracino.

STATISTICAL AND MONITORING TEAM.

A Cozzi-Lepri, P Cicconi, I Fanti, L Galli, P Lorenzini, M Shanyinda, A Tavelli. PARTICIPATING PHYSICIANS AND CENTERS IN ITALY.

A Giacometti, A Costantini, S Mazzoccato (Ancona); G Angarano, L Monno, C Santoro (Bari); F Maggiolo, C Suardi (Bergamo); P Viale, E Vanino, G Verucchi (Bologna): F Castelli, E Quiros Roldan, C Minardi (Brescia); T Quirino, C Abeli (Busto Arsizio); PE Manconi, P Piano (Cagliari); J Vecchiet, K Falasca (Chieti); L Sighinolfi, D Segala (Ferrara); F Mazzotta, S Lo Caputo (Firenze); G Cassola, C Viscoli, A Alessandrini, R Piscopo, G Mazzarello (Genova); C Mastroianni, V Belvisi (Latina): P Bonfanti, I Caramma (Lecco); A Chiodera, AP Castelli (Macerata); M Galli, A Lazzarin, G Rizzardini, M Puoti, A d'Arminio Monforte, AL Ridolfo, R Piolini, A Castagna, S Salpietro, L Carenzi, MC Moioli, C Tincati, G. Marchetti (Milano); C Mussini, C Puzzolante (Modena); A Gori, G. Lapadula (Monza); N Abrescia, A Chirianni, G Borgia, MG Guida, M Gargiulo, I Gentile, R Orlando (Napoli); F Baldelli, D Francisci (Perugia); G Parruti, T Ursini (Pescara); G Magnani, MA Ursitti (Reggio Emilia); R Cauda, M. Andreoni, A Antinori, V Vullo, A. Cingolani, A d'Avino, L Gallo, E Nicastri, R Acinapura, M Capozzi, R Libertone, G Tebano, M Zaccarelli (Roma); F Viviani, L Sasset (Rovigo); MS Mura, G Madeddu (Sassari); A De Luca, B Rossetti (Siena); P Caramello, G Di Perri, GC Orofino, S Bonora, M Sciandra (Torino); M Bassetti, A Londero (Udine); G Pellizzer, V Manfrin (Vicenza).

\section{Funding}

The authors received no funding for this work. ICONA Foundation is sponsored by unrestricted educational grants of Abbvie, BMS, Gilead, Jannsen, MSD, ViiV, Italy; the funders had no role in study design, data collection and analysis, decision to publish, or preparation of the manuscript.

\section{Availability of data and materials}

The datasets analyzed during the current study are available from the corresponding author on reasonable request.

\section{Authors' contributions}

$A S, M Z, P L$, and $A D M$ conceived the study and participated in its design and coordination. $\mathrm{AB}, \mathrm{GM}, \mathrm{FC}, \mathrm{AG}, \mathrm{EG}, \mathrm{CM}, \mathrm{PB}, \mathrm{AA}$, were responsible for data collection and were involved in the study design. PL performed the statistical analysis. AS, $M Z, F C, C M$ and ADM participated in the interpretation of data and revised the paper critically. AS drafted the manuscript. All authors read and approved the final manuscript.

\section{Ethics approval and consent to participate}

The ICONA Foundation study has been approved by IRB of all the participating centers. Sensitive data from patients are seen only in aggregate form. The research did not require approval from the ethics committee according to the Italian law since it was performed as an observational retrospective study in the context of normal clinical routines. All patients provided a written informed consent for the use of their data for research purposes. Data used for the study are openly available.

\section{Consent for publication}

Not applicable.

\section{Competing interests}

The authors declare that they have no competing interests.

\section{Publisher's Note}

Springer Nature remains neutral with regard to jurisdictional claims in published maps and institutional affiliations.

\section{Author details}

${ }^{1}$ Clinic of Infectious Diseases, University of Bari, Piazza G. Cesare, 11 -, 70124 Bari, Italy. ${ }^{2}$ Clinical Department, National Institute for Infectious Diseases "Lazzaro Spallanzani" IRCCS, Rome, Italy. ${ }^{3}$ Clinic of Infectious Diseases, "San Gerardo" Hospital - University of Milano-Bicocca, Monza, Italy. ${ }^{4}$ Clinic of Infectious Diseases, San Paolo Hospital, University of Milan, Milan, Italy. ${ }^{5}$ University Division of Infectious and Tropical Diseases, University of Brescia and Spedali Civili General Hospital, Brescia, Italy. ${ }^{6}$ Department of Epidemiology, National Institute for Infectious Diseases "L. Spallanzani," IRCCS, Rome, Italy. ${ }^{7}$ Clinic of Infectious Diseases, University of Modena and Reggio Emilia, Modena, Italy. ${ }^{8}$ Unit of Infectious Diseases, ASST Lecco, "A. Manzoni" Hospital, Lecco, Italy. Infectious Diseases Unit, Department of Internal Medicine, IRCCS Ca' Granda, Ospedale Maggiore Policlinico, Milan, Italy.

Received: 13 April 2018 Accepted: 5 July 2018 Published online: 13 July 2018

\section{References}

1. WHO. Consolidated guidelines on the use of antiretroviral drugs for treating and preventing HIV infection: recommendations for a public health approach. 2nd ed; 2016. http://www.who.int/hiv/pub/guidelines/ keypopulations-2016/en/ [accessed on 02 Dec 2016

2. UNAIDS. 90-90-90 An ambitious treatment target to help end the AIDS epidemic. 2014. http://www.unaids.org/en/resources/documents/2014/9090-90 [Accessed on 02 Dec 2016].

3. WHO. Progress report 2016. Prevent HIV, test and treat all. WHO support for country impact. 2016. http://www.who.int/hiv/pub/progressreports/2016progress-report/en/. [Accessed on 02 Dec 2016].

4. Marmot M, Allen J, Bell R, Bloomer E, Goldblatt P. WHO European review of social determinants of health and the health divide. Lancet. 2012:380(9846): 1011-29.

5. Abgrall S, Del Amo J. Effect of sociodemographic factors on survival of people living with HIV. Curr Opin HIV AIDS. 2016;11(5):501-6.

6. Istituto Superiore Di Sanità (ISS)-Centro Operativo AIDS (CoA) Aggiornamento delle nuove diagnosi di infezione da HIV e dei casi di AIDS in Italia al 31 Dicembre 2015. Not Ist Super Sanità. 2016;29(9, Suppl 1):1-52.

7. Saracino A, Lorenzini P, Lo Caputo S, Girardi E, Castelli F, Bonfanti P, Rusconi S, Caramello P, Abrescia N, Mussini C, Monno L, d'Arminio Monforte A. ICONA Foundation Study Group. Increased risk of virologic failure to the first antiretroviral regimen in HIV-infected migrants compared to natives: data from the ICONA cohort. Clin Microbiol Infect. 2016;22(3):288-e1.

8. Antiretroviral Therapy Cohort Collaboration (ART-CC). Sex differences in overall and cause-specific mortality among HIV-infected adults on antiretroviral therapy in Europe, Canada and the US. Antiv Ther. 2015;20:21-8.

9. Beer L, Mattson CL, Bradley H, Skarbinski J, Medical Monitoring Project. Understanding cross-sectional racial, ethnic, and gender disparities in antiretroviral use and viral suppression among HIV patients in the United States. Medicine. 2016:95(13):e3171.

10. Lodi S, Dray-Spira R, Touloumi G, Braun D, Teira R, D'Arminio Monforte A, Gallois A, Zangerle R, Spire B, Dabis F, Stähelin C, Termote M, Kirk O, Chêne G, Egger M, del Amo J. Socio-economic inequalities and HIV writing Group for Collaboration of observational HIV epidemiological research in Europe (COHERE) in EuroCoord. Delayed HIV diagnosis and initiation of antiretroviral therapy: inequalities by educational level, COHERE in EuroCoord. AIDS. 2014;28(15):2297-306.

11. Socio-economic Inequalities and HIV Working Group for Collaboration of Observational HIV Epidemiological Research in Europe (COHERE) in Euro-Coord. Inequalities by educational level in response to combination antiretroviral treatment and survival in HIV-positive men and women in Europe. AIDS. 2017;31(2):253-62.

12. D'Almeida KW, Lert F, Spire B, Dray-Spira R. Determinants of virological response to antiretroviral therapy: socio-economic status still plays a role in the era of CART. Results from the ANRS-VESPA 2 study, France. Antivir Ther. 2016;21(8):661-70. 
13. Lesko CR, Edwards JK, Moore RD, Lau B. A longitudinal, HIV care continuum: 10-year restricted mean time in each care continuum stage after enrollment in care, by history of injection drug use. AIDS. 2016;30(14):2227-34.

14. Valiathan R, Miguez MJ, Patel B, Arheart KL, Asthana D. Tobacco smoking increases immune activation and impairs T-cell function in HIV infected patients on antiretrovirals: a cross-sectional pilot study. PLoS One. 2014;9(5): e97698.

15. UNESCO International Standard Classification of Education standard classification. https://webgate.ec.europa.eu/fpfis/mwikis/eurydice/index.php/ Countries. [Accessed on 02 Dec 2016].

16. Althoff KN, Gebo KA, Gange SJ, et al. CD4 count at presentation for HIV care in the United States and Canada: are those over 50 years more likely to have a delayed presentation? AIDS Res Ther. 2010;7:45.

17. Glaude-Hosch JA, Smith ML, Heckman TG, Miles TP, Olubajo BA, Ory MG Sexual behaviors, healthcare interactions, and HIV-related perceptions among adults age 60 years and older: an investigation by race/ethnicity. Curr HIV Res. 2015;13(5):359-68.

18. Cornell M, Johnson LF, Schomaker M, Tanser F, Maskew M, Wood R, Prozesky H, Giddy J, Stinson K, Egger M, Boulle A, Myer L. International epidemiologic databases to evaluate AIDS-southern Africa collaboration. Age in antiretroviral therapy programmes in South Africa: a multi-Centre observational cohort study. Lancet HIV. 2015;2(9):e368-75,

19. Loutfy MR, Sherr L, Sonnenberg-Schwan U, Walmsley SL, Johnson M, d'Arminio Monforte A. Women for positive action. Caring for women living with HIV: gaps in the evidence. J Int AIDS Soc. 2013;16:18509.

20. Gandhi M, Bacchetti P, Miotti P, Quinn TC, Veronese F, Greenblatt RM. Does patient sex affect human immunodeficiency virus levels? Clin Infect Dis. 2002;35(3):31322.

21. Soon GG, Min M, Struble KA, et al. Meta-analysis of gender differences in efficacy outcomes for HIV-positive subjects in randomized controlled clinical trials of antiretroviral therapy (2000-2008). AIDS Patient Care STDs. 2012; 26(8):44453.

22. Antiretroviral Therapy Cohort Collaboration. (ART-CC). Sex differences in overall and cause-specific mortality among HIV-infected adults on antiretroviral therapy in Europe, Canada and the US. Antivir Ther. 2015;20:21-8.

23. Girardi E, Aloisi MS, Arici C, et al. Delayed presentation and late testing for HIV: demo- graphic and behavioral risk factors in a multicenter study in Italy. J Acquir Immune Defic Syndr. 2004;36:951-9.

24. Gueler A, Schoeni-Affolter F, Moser A, et al. Neighbourhood socio-economic position, late presentation and outcomes in people living with HIV in Switzerland. AIDS. 2015;29:231-8.

25. Sobrino-Vegas P, Rodriguez-Urrego J, Berenguer J, et al. Educational gradient in HIV diagnosis delay, mortality, antiretroviral treatment initiation and response in a country with universal healthcare. Antivir Ther. 2012;17:1-8.

26. Legarth $\mathrm{R}$, Omland $\mathrm{LH}$, Kronborg $\mathrm{G}$, et al. Educational attainment and risk of HIV infection, response to antiretroviral treatment, and mortality in HIV infected patients. AIDS. 2014;28:387-96.

27. Protopopescu C, Raffi F, Spire B, et al. ANRS CO8 APROCO-COPILOTE study group. Twelve-year mortality in HIV-infected patients receiving antiretroviral therapy: the role of social vulnerability. The ANRS CO8 APROCOCOPILOTE cohort. Antivir Ther. 2015;20:763-72.

28. Callander D, Bourne C, Pell C, et al. Recording the sexual orientation of male patients attending general practice. Fam Pract. 2015;32(1):35-40.

29. Joore IK, Geerlings SE, Brinkman K, van Bergen JE, Prins JM. The importance of registration of sexual orientation and recognition of indicator conditions for an adequate HIV risk-assessment. BMC Infect Dis. 2017;17(1):178.

30. Granich R, Gupta S, Hall I, Aberle-Grasse J, Hader S, Mermin J. Status and methodology of publicly available national HIV care continua and 90-90-90 targets: a systematic review. PLoS Med. 2017;14(4):e1002253.

\section{Ready to submit your research? Choose BMC and benefit from:}

- fast, convenient online submission

- thorough peer review by experienced researchers in your field

- rapid publication on acceptance

- support for research data, including large and complex data types

- gold Open Access which fosters wider collaboration and increased citations

- maximum visibility for your research: over $100 \mathrm{M}$ website views per year

At BMC, research is always in progress.

Learn more biomedcentral.com/submissions 